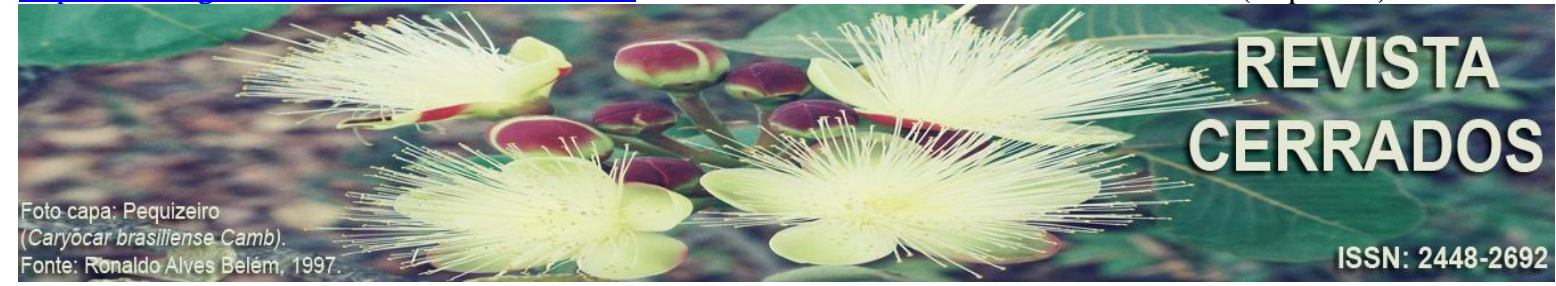

\title{
A FORMAÇÃO DA CIDADANIA ECOLÓGICA ARTICULADA À EDUCAÇÃO AMBIENTAL NA ESCOLA
}

\section{THE FORMATION OF ECOLOGICAL CITIZENSHIP ARTICULATED TO ENVIRONMENTAL EDUCATION AT SCHOOL}

\section{LA FORMATION D'UNE CITOYENNETÉ ÉCOLOGIQUE ARTICULÉE À L'ÉDUCATION À L'ENVIRONNEMENT DANS LES ÉCOLES}

\author{
Francisco Wendell Dias Costa \\ Secretaria Municipal de Educação, Anajatuba, Maranhão, Brasil \\ E-mail: <geo.fwcosta@gmail.com>.
}

Instituto Federal de Ciência e Tecnologia do Triângulo Mineiro - IFTM, Patrocínio, Minas Gerais, Brasil E-mail: <patricia.rosaa@gmail.com>.

\begin{abstract}
RESUMO
Este artigo tem por objetivo analisar a formação da cidadania ecológica articulada à Educação Ambiental na escola como proposta para a mudança de atitudes e valores sobre as questões socioambientais. A pesquisa foi desenvolvida com base em um estudo descritivo do tipo análise documental (livros, capítulos de livros e artigos acadêmicos). A escola é considerada o principal espaço para adquirir e disseminar os conhecimentos sobre a utilização da Educação Ambiental como atividade que possibilita a formação de sujeitos ecológicos, de atitude reflexiva, crítica e proativa, com intuito de agir na mitigação dos impactos socioambientais. Portanto, a prática da Educação Ambiental na escola visa a formação da Cidadania Ecológica em defesa do meio ambiente.
\end{abstract}

Palavras-chave: Escola. Cidadania. Educação Ambiental.

\begin{abstract}
This article aims to analyze the formation of ecological citizenship articulated to environmental education at school as a proposal for the change of attitudes and values about social and environmental issues. The research was carried out based on a descriptive study of document analysis type (books, book chapters and academic articles). The school is


COSTA, F. W. D; AGUIAR, P. R.

A formação da cidadania ecológica articulada à Educação Ambiental na escola

considered the main space to acquire and disseminate knowledge on the use of Environmental Education activity that enables the formation of ecological subjects, reflective, critical and proactive attitude, in order to act on mitigation of environmental impacts. Therefore, the practice of environmental education in school aims at the formation of Ecological Citizenship in favor of environmental protection.

Keywords: School. Citizenship. Environmental Education.

\section{RÉSUMÉ}

Cet article vise à analyser la formation d'une citoyenneté écologique articulée à l'Éducation à l'environnement dans les écoles en tant que proposition pour changer les attitudes et les valeurs sur les questions socio-environnementales. La recherche a été développée sur la base d'une étude descriptive de type analyse documentaire (livres, chapitres de livres et articles académiques). L'espace scolaire est considéré comme le lieu privilégié pour acquérir et diffuser des connaissances sur l'utilisation de l'Éducation à l'environnement en tant qu'activité permettant la formation de sujets écologiques, avec une attitude réflexive, critique et proactive afin d'agir dans l'atténuation des impacts socio-environnementaux. De ce fait, la pratique de l'Éducation à l'environnement dans les écoles vise à la formation de la citoyenneté écologique dans la défense de l'environnement.

Palabras-clave: Écoles. Citoyenneté. l'Éducation à L'environnement.

\section{INTRODUÇÃO}

A educação é um instrumento que procura formar o ser humano em sua completude. É também uma ação social e política, que possibilita a transformação da realidade. Nessa perspectiva, delinear-se-á algumas possibilidades que se acredita fazer sentido para que a Educação Ambiental e a Cidadania Ecológica sejam propostas de atitudes ideais para mudança na relação sociedade e natureza.

Antes, porém, faz-se necessário tecer algumas considerações sobre a Educação Ambiental como um processo mais amplo de educação e a aproximação do ato educativo na temática ambiental ao caráter político.

O debate sobre a Educação Ambiental tem produzido esforços na possibilidade de tratar a participação democrática, sobretudo na construção de uma cidadania ecológica, partindo-se do pressuposto que é necessário à efetiva sensibilização e ação vinculadas a minimizar ou mitigar os problemas socioambientais existentes, por uma gestão correta dos recursos naturais. Essas ações e práticas ambientalistas é uma resposta coletiva, na qual se 
COSTA, F. W. D; AGUIAR, P. R.

A formação da cidadania ecológica articulada à Educação Ambiental na escola

pretende buscar a real concretização de uma sociedade democrática, sendo essenciais para o senso de responsabilidade e pertencimento.

Com o auxílio da Educação Ambiental e da Cidadania Ecológica como entes fundamentais para a mudança de pensamento da sociedade, há uma tentativa de formar cidadãos ecológicos que lutam pela defesa do meio ambiente e que possam trazer medidas atenuantes aos impactos ambientais. Por este motivo, foram promovidas as Conferências e Encontros ${ }^{1}$, com objetivos de gerenciamento ambiental e aplicabilidade de projetos ligados à Educação Ambiental.

A Educação Ambiental deve ser entendida como ação política, buscando formar e incentivar cidadãos a exigir medidas atenuantes aos problemas socioambiental, com a implantação de um plano de apoio ao desenvolvimento comunitário, a fim de que se construa uma sociedade com justiça social, cidadania, ética nas relações sociais e com a natureza em prol do bem comum.

Embora a Educação Ambiental ocorra em outros espaços, mas a escola representa um espaço ideal para desenvolver a Educação Ambiental formal. É onde se busca oferecer conhecimentos, valores, responsabilidade e atributos favoráveis à prática de atividades, as quais propõem a defesa do ambiente e a possibilidade de melhorar a qualidade de vida da população, por meio da informação e conscientização. Sendo assim, um trabalho que envolva a temática ambiental no espaço escolar deve contribuir para a formação de cidadãos conscientes, propiciando ainda a construção de valores voltados para uma atuação responsável na sociedade.

O artigo tem por objetivo analisar a formação da cidadania ecológica articulada à Educação Ambiental na escola como prática que procura tornar as pessoas mais conscientes, fortalecendo a cidadania numa prática educativa ambientalista e propor também possíveis mudanças nas relações da sociedade com a natureza.

\footnotetext{
${ }^{1}$ As principais conferências sobre Meio Ambiente e Educação Ambiental são: Conferência das Nações Unidas sobre o Meio Ambiente Humano, em 1972; Conferência das Nações Unidas sobre o Ambiente e o Desenvolvimento, ou, ainda, Cúpula da Terra, a Eco-92 ou Rio-92; Cúpula Mundial sobre o Desenvolvimento Sustentável, a Rio+10, em 2002, e Conferência da ONU sobre o Desenvolvimento Sustentável, a Rio+20, em 2012; Encontro Internacional em Educação Ambiental, em 1975; Conferência Intergovernamental de Educação Ambiental, em 1977; Seminário de Educação Ambiental para América Latina, em 1979; Congresso Internacional sobre Educação e Formação Relativas ao Meio-ambiente, 1987; Conferência Internacional sobre Educação Ambiental para as Escolas de $2^{\circ}$ Grau com o tema Tecnologia e Meio Ambiente, 1989; Encontro Nacional de Políticas e Metodologias para a Educação Ambiental, 1991; Conferência Internacional sobre Meio Ambiente e Sociedade: Educação e Consciência Pública para a Sustentabilidade, 1997, dentre outros eventos (DIAS, 2010). Revista Cerrados, Montes Claros/MG, v. 18, n. 02, p. 245-274, jul./dez-2020.
} 
COSTA, F. W. D; AGUIAR, P. R.

A formação da cidadania ecológica articulada à Educação Ambiental na escola

Este artigo tem o estudo descritivo do tipo análise documental como plano de investigação, que se baseia na possibilidade de reunir uma grande quantidade de informação e dados (TRIVIÑOS, 1987). Para o complemento da pesquisa, foram desenvolvidos os seguintes procedimentos metodológicos: levantamento e análise de material bibliográfico específico (livros e capítulos de livros) e de artigos, trabalhos acadêmicos (monografia, dissertações e teses) com informações sobre a temática desenvolvida a fim de fundamentar o trabalho.

Posto isso, foram analisados alguns trabalhos de Educação Ambiental em escolas, que foram publicados em forma de artigos em revistas científicas e em livros. Entretanto, como não é objetivo deste artigo divulgar todos esses trabalhos, considera-se pertinente a citação dos projetos de Educação Ambiental em escolas desenvolvidos por Boher e Krob (2012) e Mello (2013), que apresentaram resultados positivos.

\section{HISTÓRICO DA EDUCAÇÃO AMBIENTAL E A SITUAÇÃO ATUAL}

Existem relatos de épocas remotas sobre a preocupação da população em preservar e conservar os recursos naturais com medidas e atitudes semelhantes aos moldes atuais da Educação Ambiental. Entretanto, para este trabalho procurou-se analisar a partir da segunda metade do século XX, quando a baía de Minamata no Japão foi contaminada, em 1951, por metais pesados originados de efluentes industriais, contaminando os pescados da região e intoxicando milhares de cidadãos japoneses. A partir de então, diversas mobilizações espalhadas pelo mundo foram realizadas em defesa do meio ambiente, quando o indivíduo se tornou cada vez mais consciente, ético e crítico perante as questões socioambientais (PROTÁZIO, 2011).

E uma dessas formas de mobilização se dá pela educação, que permite aos indivíduos pensarem de forma crítica e reflexiva. Diante da problemática socioambiental no planeta, o atual estágio de conscientização da população mobilizou diversos setores da sociedade em prol da preservação e conservação do meio ambiente. Prova disto, pontua-se o fato de que nas últimas quatro décadas realizaram-se eventos que possibilitaram a discussão e difusão dessa problemática.

No final da década de 1960, foi elaborado um documento por cientistas dos países industrializados denominado "Relatório do Clube de Roma" conhecido também como 
COSTA, F. W. D; AGUIAR, P. R.

A formação da cidadania ecológica articulada à Educação Ambiental na escola

"Limites ao Crescimento". A ideia seria de impor limites ao padrão de crescimento industrial vigente; buscar meios para conservação dos recursos naturais; controlar o crescimento da população e modificar a mentalidade de consumo exagerado, fundamentando-se na proposta de "crescimento zero", na qual seria a única alternativa para salvar o mundo de uma “catástrofe ambiental” (FOGLIATTI; FILIPPO; GOUDARD, 2004).

Reigota (2009, p. 23) afirma que "um dos méritos dos debates das conclusões do Clube de Roma foi colocar o problema ambiental em nível planetário”. A grande marca decorrente dos resultados do Clube de Roma foi a realização, em 1972, em Estocolmo (Suécia), da Primeira Conferência Mundial de Meio Ambiente Humano, promovida pela Organização das Nações Unidas (ONU). A poluição foi o tema central desse evento, sendo ocasionada pelos dejetos industriais e os males que ela causa para o ambiente.

Desse evento, criou-se a denominada "Declaração sobre o Meio Ambiente Humano", surgindo, portanto, o conceito de "Ecodesenvolvimento". O referido termo apresenta relevante importância, uma vez que trata das questões ambientais e humanas, indicando que o desenvolvimento dos países deve vir correlacionado com justiça social, eficiência econômica e prudência ecológica (FOGLIATTI; FILIPPO; GOUDARD, 2004).

A Conferência de Estocolmo é considerada um marco no despertar da consciência ecológica mundial para a crise ambiental e no desenvolvimento propositivo de alternativas para os problemas ambientais. Nessa reunião, foram criados vários programas visando à preservação ecológica, tais como: Programa das Nações Unidas para o Meio Ambiente PNUMA, Comissão Mundial sobre o Meio Ambiente e o Desenvolvimento - CMMAD e o Programa Observação da Terra - Earthwatch. Tais fatos, acordos e programas estabeleceram definitivamente a temática ambiental na agenda e nas discussões da ONU.

Na conferência de 1972, ficou decidido que se deve educar o cidadão na tentativa que ele indique possíveis soluções para os problemas ambientais. Reigota (2009) afirma que nesse momento surgiu o que se chamou de 'Educação Ambiental'. Visto sua importância, foi realizado em 1977 na cidade de Tbilisi, ex-URSS, o mais importante evento internacional em favor da Educação Ambiental, conhecido como a 'Primeira Conferência Intergovernamental sobre Educação Ambiental', sendo responsável pela elaboração de princípios, estratégias e ações norteadores para a aplicabilidade da Educação Ambiental.

Por ocasião deste evento, foi recomendado que a prática da Educação Ambiental deveria levar em consideração todos os aspectos (políticos, sociais, econômicos, científicos, 
COSTA, F. W. D; AGUIAR, P. R.

A formação da cidadania ecológica articulada à Educação Ambiental na escola

tecnológicos, éticos, culturais e ecológicos) dentro da perspectiva inter e multidisciplinar. Enfatizou-se ainda que a educação é importante para compreensão dos problemas ambientais, sendo indicado alguns critérios que poderiam contribuir na orientação da Educação Ambiental. O documento elaborado na Primeira Conferência Intergovernamental sobre Educação Ambiental apresentou recomendações essenciais para o desenvolvimento da Educação Ambiental (DIAS, 2010).

Dentre as recomendações constituintes do referido documento destaca-se a proposição de que a Educação Ambiental é o resultado de uma orientação e articulação de diversas disciplinas e experiências educativas, que facilitam a percepção integrada do meio ambiente, tornando possível uma ação mais racional e capaz de responder às necessidades sociais (REIGOTA, 2009).

Outras recomendações tratam dos princípios básicos da Educação Ambiental ao considerar o meio ambiente em sua totalidade, ou seja, em seus aspectos naturais e os criados pelo homem (tecnológico e social, econômico, políticos, histórico-cultural, moral e estético); assim como destaca a complexidade dos problemas ambientais e a necessidade de desenvolver o senso crítico e as habilidades necessárias para resolver tais problemas; utilizar diversos ambientes educativos e uma ampla gama de métodos para comunicar e adquirir conhecimentos sobre o meio ambiente, acentuando devidamente as atividades práticas e as experiências pessoais (DIAS, 2010).

Loureiro et al. (2009) afirma que um dos objetivos da Educação Ambiental é lograr que os indivíduos e a coletividade compreendam a natureza composta pelo ambiente natural e pelo ambiente criado pelo homem, como resultado da integração de seus aspectos biológicos, físicos, sociais, econômicos e culturais. Ademais, espera-se que adquiram conhecimentos, valores, comportamentos e habilidades para participar responsável e eficazmente da prevenção e solução dos problemas ambientais e da gestão da qualidade do meio ambiente. Dessa forma, a Educação Ambiental deveria suscitar uma vinculação mais estreita entre os processos educativos interdisciplinares e a realidade, estruturando suas atividades em torno dos problemas concretos que se impõem à comunidade.

Catalão (2009) cita a 'Comissão Mundial sobre o Meio Ambiente e Desenvolvimento' que, em 1987, elaborou um relatório denominado "Nosso Futuro Comum", também conhecido como Relatório de Brundtland. Deste relatório surgiu o conceito de 
COSTA, F. W. D; AGUIAR, P. R.

A formação da cidadania ecológica articulada à Educação Ambiental na escola

'Desenvolvimento Sustentável' voltado ao atendimento às necessidades atuais sem comprometer o atendimento das necessidades das futuras gerações.

O Desenvolvimento Sustentável se configura como uma estratégia ou modelo para as sociedades, levando-se em consideração os aspectos econômicos e ecológicos, orientando o desenvolvimento tecnológico, os padrões de consumo, na superação dos déficits sociais e na possibilidade de frear a exploração predatória dos recursos naturais.

Passados 20 anos da Conferência de Estocolmo, realizou-se no Rio de Janeiro, em 1992, a 'Conferência Mundial das Nações Unidas sobre o Meio Ambiente', a qual ficou conhecida também como Eco-92. Santilli e Santilli (2009) falam que este evento foi um marco na concepção e formulação de documentos com fundamentos e diretrizes de políticas públicas socais e ambientais para o mundo.

Durante a Eco-92 foram aprovados documentos com propósito de consolidar o desenvolvimento sustentável proposto pelo Relatório Brundtland, tais como: a 'Declaração do Rio Janeiro sobre Meio Ambiente e Desenvolvimento', a 'Convenção sobre Diversidade Biológica', a 'Convenção sobre as Mudanças Climáticas e Agenda 21', além do 'Tratado sobre a Educação Ambiental para as Sociedades Sustentáveis'. Este tratado expõe além de princípios a serem defendidos, "um plano de ação para os educadores ambientais, estabelecendo, deste modo, uma relação entre políticas públicas de Educação Ambiental e a sustentabilidade" (JACOBI, 2003, p. 06).

Reigota (2009) afirma que após a Conferência do Rio de Janeiro em 1992, foi estabelecido dois marcos importante nas questões ambientais: O primeiro deles é um componente da 'Convenção sobre Mudanças Climáticas da Eco-92', assinado em 1997, denominado Protocolo de Kyoto. O objetivo maior do protocolo objetivo seria evitar as interferências antropogênicas perigosas no sistema climático, cabendo às nações industrializadas se comprometessem em reduzir as emissões de gases potencializadores do efeito estufa. O segundo marco foi estabelecido em 2002, em Johanesburgo, África do Sul, quando da ocorrência da Conferência das Nações para o Desenvolvimento Sustentável, conhecida como Rio+10. Esta Conferência teve como principal objetivo avaliar as aplicações e os progressos das diretrizes e propostas da Eco-92, sobretudo à implantação da Agenda 21. Foram discutidas metas relacionadas ao acesso a água potável e tratada, ao saneamento básico, gerenciamento dos resíduos tóxicos e ao uso de fontes alternativas de energia (SANTILLI; SANTILLI, 2009). 
COSTA, F. W. D; AGUIAR, P. R.

A formação da cidadania ecológica articulada à Educação Ambiental na escola

A Rio+10 possibilitou a participação ativa da população africana nas discussões sobre os problemas que a África vive, sejam eles as guerras civis, a grande quantidade de contaminados pelo HIV, a poluição do ar e da água, os elevadíssimos índices de analfabetismo e a pobreza extrema de grande parte da população (REIGOTA, 2009). Outra conferência de igual importância foi realizada em Copenhague, na Dinamarca, conhecida como 'Convenção do Clima', também conhecida como COP-15, cujo propósito seria estabelecer novos rumos para um acordo internacional, para a substituição do Protocolo de Kyoto, visto que o prazo de validade do Protocolo expirou no ano de 2010.

Em 2012 ocorreu a 'Conferência das Nações Unidas sobre Desenvolvimento Sustentável', conhecida como Rio+20. Além de refletir sobre as ações adotadas desde 1992, o evento desejava estabelecer as principais diretrizes para orientar o Desenvolvimento Sustentável pelos próximos vinte anos, abarcando suas dimensões econômica, social e ambiental.

As Nações Unidas definiram como temas para a Rio+20: a Economia Verde no contexto do desenvolvimento sustentável e da erradicação da pobreza e Estrutura Institucional para o Desenvolvimento Sustentável. Sobre o primeiro tema citado, o desafio proposto à comunidade internacional é o de pensar um novo modelo de desenvolvimento, que seja ambientalmente responsável, socialmente justo e economicamente viável. Assim, a conhecida "Economia Verde" passa a ser considerada uma ferramenta para o desenvolvimento sustentável. No documento final da conferência Rio+20 foram expostos 283 tópicos considerados relevantes para a busca do desenvolvimento sustentável e o combate à pobreza (FERNANDES; LINS; VILLAS-BÔAS, 2012).

Visando contribuir com a legislação federal, os estados brasileiros elaboraram seus Planos Estaduais de Educação Ambiental ${ }^{2}$, com objetivo de: promover o engajamento das pessoas, com capacitação individual e coletiva, politicamente críticas-reflexivas, na construção de uma sociedade sustentável do ponto de vista ambiental, social, ético, econômico e cultural, com pessoas e atuantes na busca por justiça socioambiental; promover programas, projetos e ações de educação ambiental; incentivar a formação inicial e continuada de professores e educadores de todos os níveis e modalidades de ensino, como aos gestores

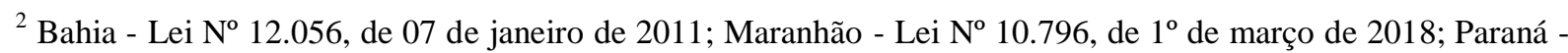
Lei $N^{\circ} 17.505$, de 16 de janeiro de 2013; Mato Grosso - Lei No 10.903, de 07 de junho de 2019; São Paulo - Lei $\mathrm{N}^{\mathrm{o}} 12.780$, de 30 de novembro de 2007.
}

Revista Cerrados, Montes Claros/MG, v. 18, n. 02, p. 245-274, jul./dez-2020. 
COSTA, F. W. D; AGUIAR, P. R.

A formação da cidadania ecológica articulada à Educação Ambiental na escola

dos sistemas de educação e de meio ambiente; fomentar pesquisas e o desenvolvimento de metodologias para a Educação Ambiental.

A problemática ambiental está evidente e a consciência da população a esse respeito também, por isso a comunidade internacional promoveu essas reuniões com propósito de discutir quais seriam as melhores medidas e mecanismos. Nesse sentido, a Educação Ambiental pode criar cidadãos críticos, reflexivos e atuantes, com uma formação de cidadão ecológico. Entretanto, não significa que ela irá atenuar todos os problemas ambientais nas diferentes escalas geográficas, por outro lado pode ser ações visando a serem utilizadas na defesa do meio ambiente.

\section{A FORMAÇÃo DA CIDADANIA ECOLÓGICA ARTICULADA À EDUCAÇÃo AMBIENTAL}

O 'Tratado de Educação Ambiental para Sociedades Sustentáveis e Responsabilidade Global' foi elaborado durante a ECO-92, definindo a Educação Ambiental como ação que

deve tratar das questões globais críticas, suas causas e inter-relações em uma perspectiva sistêmica, em seu contexto social e histórico. Aspectos primordiais relacionados com o desenvolvimento e o meio ambiente, tais como população, saúde, paz, direitos humanos, democracia, fome, degradação da flora e da fauna, devem ser abordados dessa maneira (CASCINO, 2003, p. 45).

Reigota (2009) entende a importância da Educação Ambiental ao afirmar que é uma prática considerada preponderante para uma ação política, pois ela se propõe a preparar cidadãos que deve adotar como princípios a reivindicação por justiça social, cidadania e ética nas relações sociais.

Carvalho (2008) fala que diante da problemática ambiental está evidente a formação de uma consciência da população e elaboração de propostas educativas com objetivos que perpassam pela função social e política, buscando a formação de um cidadão crítico e reflexivo. O propósito destas ações se estabelece a fim de transformar a realidade social, política e ambiental de uma parcela da população, partindo-se da premissa de que a mudança de pensamento, atitudes, ações e posturas ocorrem primeiramente em escala local. Sendo assim, a Educação Ambiental tem contribuído para a formação de um cidadão consciente com relação às questões ambientais (CATALÃO, 2009).

Revista Cerrados, Montes Claros/MG, v. 18, n. 02, p. 245-274, jul./dez-2020. 
COSTA, F. W. D; AGUIAR, P. R.

A formação da cidadania ecológica articulada à Educação Ambiental na escola

A Educação Ambiental se configura como uma práxis educativa, social e política, tendo como principal finalidade a construção de valores, conceitos, habilidades e atitudes, que deve contribuir para numa nova relação sociedade-natureza. Configura-se também, como um elemento essencial e estratégico na formação da consciência humana, na tentativa de formar cidadãos críticos, reflexivos e atuantes (LOUREIRO, 2008). Deste modo, a Educação Ambiental constitui-se em uma ferramenta de reflexão para àqueles que acreditam na transformação das atitudes da população.

Nessa perspectiva, são viáveis

as propostas pedagógicas centradas na conscientização, mudança de comportamento, desenvolvimento de competências, capacidade de avaliação e participação dos educandos, propiciando o ganho de conhecimentos, mudança de valores e aperfeiçoamento de habilidades (REIGOTA, 1998 Apud JACOBI, 2003, p. 196).

Entretanto, a Educação Ambiental tende a questionar o conceito de educação vigente, pois se configura como um ato crítico e uma alternativa aos processos pedagógicos conservadores. Como uma prática política, há a possibilidade de formar cidadãos conscientes dos seus direitos e deveres.

Há uma relação direta entre meio ambiente, educação e cidadania, demandando a emergência de novos saberes para apreender os processos socioambientais mais complexos. Nesse sentido, a Educação Ambiental se configura como um desafio ao fortalecimento da cidadania da população corresponsável na defesa do meio ambiente e na qualidade de vida (JACOBI, 2003).

Loureiro (2008) faz uma abordagem histórica sobre a noção de cidadania desde a Grécia Clássica, quando o conceito de cidadão se referia àquele que participava da formação do governo e com interferência na esfera pública, ficando excluídos escravos e mulheres, dentre outros. Já no século XVIII, há uma perspectiva de relação de cidadania com direitos civis e políticos e sociais, que nos dão a ideia de direitos individuais de liberdade, igualdade, de prosperidade, de ir e vir e de segurança. Por outro lado, no século XIX os direitos políticos se referem às diversas formas de liberdade de associação, de organização política e eleitoral. No século XX a noção de cidadania vincula-se ao direito de trabalho, à educação, à saúde, à aposentadoria e ao sistema previdenciário.

A cidadania foi conquistada historicamente, reforçando a ideia de que os indivíduos devem se "apropriar" dos bens socialmente criados, na tentativa de assegurar seus 
COSTA, F. W. D; AGUIAR, P. R.

A formação da cidadania ecológica articulada à Educação Ambiental na escola

direitos civis. A cidadania é assumida a partir daqui como algo que se constrói permanentemente, incorporando dimensões e significados com participação popular no combate às injustiças socioeconômicas e ambientais.

Ao atribuir a importância da cidadania nas questões ambientais fica claro uma nova tomada de consciência e atitudes, sendo muito bem exposta na chamada Ecocidadania ou Cidadania Planetária que é utilizada para

expressar a inserção da ética ecológica e seus desdobramentos no cotidiano, em um contexto que possibilita a tomada de consciência individual e coletiva das responsabilidades tanto locais e comunitárias quanto globais, tendo como eixo central o respeito à vida e a defesa do direito a esta em um mundo sem fronteiras geopolíticas (LOUREIRO, 2008, p. 76).

Nessa perspectiva, relacionar 'Educação Ambiental' e 'Cidadania' é uma atividade que necessita

atribuir a identidade e o pertencimento a uma coletividade. É uma atitude que contribui para a formação e exercício da cidadania, referindo-se a uma nova forma de encarar a relação do homem com a natureza. [...] A Educação Ambiental para a cidadania representa a possibilidade de motivar e sensibilizar as pessoas para transformar as diversas formas de participação da sociedade e de concretização de uma proposta de sociabilidade baseada na educação para a participação (JACOBI, 2003, p. 198-199).

Para se formar um cidadão consciente, crítico, competente e proativo é preciso compreender que a educação é uma forma de intervenção no e para o mundo, englobando os seus aspectos sociais, econômicos, políticos, culturais, éticos e estéticos. Fica claro que a Educação Ambiental se tornou um importante processo de ensino-aprendizagem para o exercício da cidadania, de responsabilidade social e política. O propósito é construir novos valores e novas relações dos seres humanos com a natureza, em prol da melhoria da qualidade de vida para todos os seres vivos (PHILIPPI JUNIOR; PELICIONI, 2002).

A prática da cidadania nas questões ambientais deve incorporar responsabilidades éticas, políticas, sociais, econômicas e ecológicas, tendo em vista o respeito, a defesa e o direito à vida no cenário mundial, regional e local. Para enfatizar o papel da cidadania nas questões ambientais, forma-se a cidadania ecológica, na qual se configura como uma prática educativa ambientalista (LOUREIRO, 2008).

Para a participação do cidadão em questões ambientais há necessidade da efetiva motivação e mobilização, considerando que 
COSTA, F. W. D; AGUIAR, P. R.

A formação da cidadania ecológica articulada à Educação Ambiental na escola

os processos da cidadania e da participação guardam entre si uma relação de interdependência e complementaridade fundamental à afirmação e ao exercício da democracia genuína, pois (...) a cidadania necessita da participação social para assegurar sua concretização, dinamismo, crescimento e maturação (...) a participação social pressupõe, para sua concretização e exercício, a cidadania entendida como conquista e reconhecimentos de direitos. Participar significa fazer parte e tomar parte, significa influir ativamente na escola e na construção dos destinos sociais e na solução dos problemas vivos pela comunidade (CASTRO; BAETA, 2008, p. 134).

Os autores supracitados tentaram defender a tese de que um dos desafios para a formação da cidadania ecológica está na participação social nas questões ambientais e para a sua concretização é necessário redefinir a consciência cidadã e a cidadania ativa. Ficou evidente que existe uma relação íntima entre as questões ambientais, educação e cidadania.

As ações reflexivas sobre a complexidade ambiental permitiram que o exame de valores e percepções das práticas sociais auxilie na transformação e na atitude das pessoas através de práticas educativas. Estas devem vir correlacionadas com os movimentos sociais de caráter ecológicos. Para Carvalho (2008), a educação promove uma aprendizagem que gera processos de formação do sujeito humano. O resultado dessa aprendizagem é a conscientização ambiental e, para isso, propõe à formação do sujeito ecológico que possui traços, valores e ânimo para lutar pelos projetos e ideais ecológicos para difundi-los na sociedade.

A constituição e o fortalecimento da cidadania ecológica ativa perpassam pela (re)construção dos direitos e deveres dos sujeitos. Desse modo,

cabe destacar que a Educação Ambiental assume cada vez mais uma função transformadora, na qual os indivíduos são corresponsabilização dos indivíduos torna-se um objetivo essencial para promover um novo tipo de desenvolvimento - o desenvolvimento sustentável. [...] O caminho a ser desenhado passa por uma mudança no acesso à informação e por transformações institucionais que garantam acessibilidade e transparência na gestão (JACOBI, 1993-1995).

Essa abordagem propõe definir e seguir os objetivos do desenvolvimento sustentável na perspectiva crítico e transformador dos homens. Para tanto, devem ser potencializados os saberes e conhecimentos formais e não-formais necessários para a promoção ativa e participativa na defesa do no meio ambiente. 
COSTA, F. W. D; AGUIAR, P. R.

A formação da cidadania ecológica articulada à Educação Ambiental na escola

\section{AS FRENTES CONCILIADORAS DA EDUCAÇÃO AMBIENTAL}

O Ministério do Meio Ambiente (MMA) publicou, em 2004, o livro Identidades da Educação Ambiental Brasileira em que demonstrou diversas frentes que devem conciliar educação, meio ambiente e cidadania. Nesse livro, a Educação Ambiental é apresentada em três vertentes: crítica (GUIMARÃES, 2004), transformadora (LOUREIRO, 2004), emancipatória (LIMA, 2004). Sem desmerecer e sem reduzir os brilhantes trabalhos dos autores, é possível identificar pelo menos duas formas de se pensar e de se fazer a Educação Ambiental: uma como conservadora ou conservacionista, e, outra como crítica, transformadora ou emancipatória.

A vertente conservadora ou conservacionista expõe a ideia de que a solução dos problemas socioambientais dependeria, basicamente, da transformação individual dos sujeitos, centrada numa educação individualista. Os adeptos dessa vertente buscam mudanças comportamentais, objetivando a formação de novos hábitos "ambientalmente corretos e sustentáveis". Cria-se, portanto, a falácia de um "capitalismo verde e humanizado", indicando que as soluções para os problemas socioambientais advêm pela transformação individual dos sujeitos, ou seja, a transformação da sociedade seria alcançada no momento em que "cada um fizesse a sua parte" (GUIMARÃES, 2004; NUNES; FREITAS, 2011).

A Educação Ambiental para a vertente crítica, transformadora ou emancipatória adota uma perspectiva holística direcionada para a compreensão de que as problemáticas socioambientais têm uma causa estrutural fruto do modo de produção desigual capitalista. Tais problemáticas seriam superadas por meio de ações coletivas e organizadas. A Educação Ambiental, nesta perspectiva, apresenta um caráter político e função social, potencializando uma visão crítica, que imprime nos indivíduos um caráter reivindicatório na busca por uma transformação da sociedade (LIMA, 2004).

A Educação Ambiental crítica, transformadora e emancipatória é "[...] uma síntese das propostas pedagógicas que têm como fundamento a crítica da sociedade capitalista e da educação como reprodutora das relações sociais injustas e desiguais" (LOUREIRO et al., 2009, p. 1).

Nesse sentido, é possível afirmar que esta vertente é considerada a mais ideal para articular cidadania ecologia e Educação Ambiental na escola, sendo formadora de uma consciência ecológica, com intuito de formar cidadãos críticos, reflexivos e atuantes na defesa 
COSTA, F. W. D; AGUIAR, P. R.

A formação da cidadania ecológica articulada à Educação Ambiental na escola

do meio ambiente e na tentativa de atenuar os problemas ambientais já existentes e evitar os que hão de aparecer.

\section{EDUCAÇÃO AMBIENTAL NA ESCOLA: AÇÃO CONCRETA}

As questões ambientais têm ganhado espaço junto à opinião pública de forma geral, principalmente, devido aos efeitos prejudiciais das atividades humanas sobre o meio, afetando o conjunto de seres vivos, inclusive o ser humano. Nesse sentido, encontrar formas que contribuam para ampliar a percepção das pessoas sobre os problemas ambientais, suas razões, surgimento e efeitos mostra-se uma necessidade fundamental em busca de uma ética e de uma consciência ambiental capazes de equilibrar a relação entre sociedade-natureza.

A escola é um lugar privilegiado para tratar dessas questões, pois possibilita o acesso e reflexão aos conhecimentos de forma metódica e sistematizada, contribuindo para formar padrões de pensamento daqueles que, em breve, farão uso dos recursos e serviços ambientais. Almeida e Suassina (2005) ressaltam que é obrigação da escola educar e preparar o cidadão para reivindicar justiça social e ética nas relações sociais e com a natureza, ou seja, desenvolver a consciência ambiental nos alunos.

A educação escolar tem a função de gerar espaços para possíveis mudanças sociais, culturais, ambientais, políticas e econômicas. Trata-se de uma educação centrada na vida, no seu contexto físico, biológico, cultural, social e econômico, na qual o ser humano reaprenda conviver com a fauna, a flora e os recursos naturais sentindo-se parte integrante da natureza.

Na educação formal cabe à escola a responsabilidade de capacitar os educandos para o mundo, buscando acompanhar a atual revolução da humanidade, as transformações sociais, culturais, geográficas e problemas ambientais, que estão ocorrendo de forma rápida e crescente. Por isso, é de total importância que se trabalhe a Educação Ambiental na escola, visto que é um espaço de construção de conhecimento e formação de cidadãos responsáveis, reflexivos e críticos.

A Lei federal $N^{\circ}$ 9795/99, que instituiu a Política Nacional de Educação Ambiental, em seu Artigo $1^{\circ}$, entende que Educação Ambiental é a somatória de processos, por meio do qual o indivíduo e a coletividade constroem valores sociais, conhecimentos, habilidades, atitudes e competências voltadas para a conservação do meio ambiente; sendo, 
COSTA, F. W. D; AGUIAR, P. R.

A formação da cidadania ecológica articulada à Educação Ambiental na escola

portanto, um bem de uso comum do povo, essencial à sadia qualidade de vida e à sustentabilidade, devendo estar presente em todos os níveis e modalidades de ensino, tanto em seu caráter formal como informal (BRASIL, 1999).

A inclusão da Educação Ambiental no currículo escolar, de forma transversal, causa um processo de inovação educativa englobando todo o conjunto do coletivo escolar (professores, alunos e comunidade) e as instâncias decisórias e responsáveis das secretarias de educação, no âmbito estadual e municipal, com apoio das Delegacias do MEC nos estados e de outras entidades interessadas no tema (SANTOS, MEDINA, 1999).

A temática ambiental deve permear todas as disciplinas do currículo escolar como tema transversal, trabalhando a interdisciplinaridade e transdisciplinaridade e estar contextualizada com a realidade da comunidade. É na escola que a temática ambiental ajudará o educando a realizar correlações dos fatos e a ter uma visão do mundo em que vive, a fim de fomentar a criatividade, o raciocínio, a reflexão e a criticidade dos alunos (BRASIL, 1997). Por outro lado, a escola ainda não incorporou ao seu cotidiano o meio ambiente como tema transversal conforme preconizam os Parâmetros Curriculares Nacionais e a Política Nacional de Educação Ambiental.

A Educação Ambiental na escola deve promover reflexão e o conhecimento, desempenhando o papel de conscientizar por meio de atividades práticas, operando tarefas diárias com ações pautadas na valorização dos bens naturais para as gerações atuais e futuras, na perspectiva do desenvolvimento sustentável (REIGOTA, 1998; BRITO, 2007).

Nessa perspectiva, Gonçalves e Diehl (2012) afirmam que a escola, dentre outras obrigações, tenta auxiliar na formação de indivíduos críticos-reflexivos e participativos na construção de um tripé: educação-coletividade-ambiente. As ações educativas com viés ambientais buscam aproximar da realidade dos alunos e da comunidade escolar.

Ab’Saber (2001) considera que uma educação pode ser considerada significativa a partir das interferências da disciplina Geografia ao fazer com que os alunos possuem uma relação de intimidade com o lugar e seus significados. Dessa forma, fazer os alunos entender e refletir a partir dos conhecimentos adquiridos em sala de aula e perceberem o que é pertinente na forma de agir na comunidade para buscar alternativas na tentativa de atenuar os problemas ambientais verificados.

Considerando a importância da Educação Ambiental na construção de valores, hábitos, nas formas de relacionamentos e de um processo de sensibilização e conscientização 
COSTA, F. W. D; AGUIAR, P. R.

A formação da cidadania ecológica articulada à Educação Ambiental na escola

dos alunos, algumas reflexões e intervenções didáticas acerca de experiências através de projetos na temática ambiental em escolas públicas que tiveram resultados significativos, seja pelo caráter inovador, pelo reconhecimento social conquista ou pela abrangência podem ser tomadas como exemplos. Entretanto, para não se alongar muito nessa discussão, foi decidido citar somente dois exemplos de intervenções de importante relevância para a discussão apresentada neste artigo.

Toda experiência educativa de caráter ambiental apresenta uma riqueza de análise, como ocorre com o Instituto de Curicaca que desde 2006 desenvolve a Ação Cultural de Criação Saberes e Fazeres da Mata Atlântica como um processo educativo complementar ao currículo de escolas públicas do estado do Rio Grande do Sul. Os projetos visaram o envolvimento e capacitação de alunos, professores (mediadores ou facilitadores), diretores e demais funcionários das secretarias municipais e estaduais de educação e os gestores públicos em prol da conservação da biodiversidade, de valorização da cultura local e na tomada de decisão na gestão socioambiental das Unidades de Conservação desse estado (BOHER; KROB, 2012).

O projeto Lixo urbano e seus impactos ambientais desenvolvido na Escola Estadual Prof. a Josepha Cubas da Silva localizada no município de Ourinhos-SP, possibilitou os alunos ampliar visões e saberes acerca da problemática causada pelo consumo exagerado e pela produção de lixo nas escalas global e regional, relacionando aos problemas enfrentados na vida cotidiana dos moradores dos bairros do município. Nessa proposta foi discutido sobre a importância da implantação da coleta seletiva para a cidade e a presença do aterro controlado para o destino do lixo, que em virtude do crescimento da cidade pode trazer problemas socioambientais (contaminação dos lençóis freáticos pela produção do chorume, inviabilizando o consumo de água; transmissão de doenças por roedores e pelo mosquito Aedes aegypti, dentre outros) e modificação da paisagem urbana (MELLO, 2013).

A dimensão participativa desses projetos envolve o entendimento de um processo educativo que envolveram uma perspectiva com rigor teórico-metodológico, experiências cotidianas, ensino, extensão e superação da fragmentação dos conhecimentos (TOZONIREIS; VASCONCELLOS, 2014). É a representatividade daquilo que articula três dimensões: pesquisa-ação-participativa na produção de reflexões, análises e saberes ambientais transformadores sobre a realidade educativa, segundo a visão de Moreno (1972), Feire (1981), Thiollent (2000), Loureiro (2007), entre outros. 
COSTA, F. W. D; AGUIAR, P. R.

A formação da cidadania ecológica articulada à Educação Ambiental na escola

Um dos principais objetivos é formar um pensamento crítico, reflexivo e inovador, promovendo a transformação e a construção de uma sociedade ecologicamente justa. Sobre essa questão, para conscientizar é importante que os educadores cultivem as ideias ecológicas em sua prática educativa, tentando formar os sujeitos ecológicos (CARVALHO, 2005).

Fica claro que a Educação Ambiental é um processo de ensino-aprendizagem para o exercício da cidadania, da responsabilidade social e política. Sendo praticada tanto na educação escolar, como também nos demais setores da sociedade. Para tanto, o propósito é construir novos valores e novas relações dos seres humanos com a natureza, em prol da melhoria da qualidade de vida para todos os seres (PHILIPPI JUNIOR; PELICIONI, 2002).

\section{CONSIDERAÇÕES FINAIS}

É importante concordar que o papel da Educação Ambiental, tendo como base a formação de um pensamento crítico, reflexivo e inovador, é uma das formas que busca promover a transformação e a construção de uma sociedade ecologicamente justa. Para essa questão se concretizar é importante que os educadores cultivem ideias e sensibilidades ecológicas em sua prática educativa, tentando formar sujeitos ecológicos.

Daí a necessidade de se pensar caminhos que favoreçam os grupos escolares, de modo que conheçam os problemas do ambiente local e possam desenvolver atividades, que incentivem a refletir sobre o meio em que estão inseridos, além de visualizar os possíveis espaços de atuação e, efetivamente, compreender o seu papel para a conservação e preservação do meio ambiente.

Para que isso ocorra, é necessário que a prática ambiental seja desenvolvida no cotidiano escolar e que favoreça o processo participativo, preparando os alunos para atuar como agente transformador da sua realidade. É evidente que, por meio da Educação Ambiental formal, os educandos se tornam mais atuantes em um propósito que busca atingir uma parcela maior da população.

Portanto, a proposta da formação ecológica articulada à Educação Ambiental na escola está diretamente vinculada ao processo do exercício da cidadania fundamentada em uma prática/práxis. 
COSTA, F. W. D; AGUIAR, P. R.

A formação da cidadania ecológica articulada à Educação Ambiental na escola

Sobre isso, Loureiro (2004) comenta que Educação Ambiental é o meio educativo pelo qual se pode compreender de modo articulado as dimensões ambientais e sociais, problematizar a realidade, buscando raízes da crise civilizatória. Sendo assim, a escola se configura como o espaço transformador, que pode desempenhar um papel visando a transformação da consciência do homem, agindo na preservação e conservação do meio ambiente.

\section{REFERÊNCIAS}

AB'SABER, Aziz. Entrevista concedida à Revista Nova Escola de Janeiro de 2001. Disponível em: aprendizesdanatureza.blogspot.com/.../entrevista-com-aziz-absaber.html. Acesso em: 10/07/2015.

ALMEIDA, Arthur José Medeiros de; SUASSUMA, Dulce Maria Figueira de Almeida. A formação da consciência ambiental e a escola. Revista eletrônica do mestrado em educação ambiental, [S./l.], v. 15, p. 107-129, Jul./Dez. 2005. Disponível em:

http://www.remea.fugr.br. Acesso em: 10/09/2015.

BRASIL. Parâmetros Curriculares Nacionais: meio ambiente e saúde. Brasília: MEC/SEF, 1997.

BRASIL. Lei no 9795 de 27 de abril de 1999. Dispõe sobre a Política Nacional de Educação Ambiental. Disponível em: http://www.planalto.gov.br/ccivil_03/Leis/L9795.htm. Acesso em: 20/07/2015.

BOHRER, Patrícia Vianna; KROB, Alexandre José Diehl. Instrumentos de avaliação de resultados: conhecendo e aperfeiçoando a atuação do educador ambiental e do Instituto Curicaca. In: LISBOA, Cassiano Pamplona; KINDEL, Eunice Aita Isaia (Orgs.). Educação Ambiental: da teoria à prática. Porto Alegre: Mediação, 2012, p. 83-98.

BRITO, Lenir Cardoso. A percepção da paisagem do Município de Viana/MA pelos estudantes da $1^{\text {a }}$ série do C.E.M. Nossa Senhora da Conceição. 2007. 62 f. Monografia (Especialização em Educação Ambiental e Gestão Participativa em Recursos Hídricos), Departamento de Química, Centro Federal de Educação Tecnológica do Maranhão, São Luís, 2007.

CARVALHO, Isabel Cristina de Moura. A invenção do sujeito ecológico: identidades e subjetividade na formação dos educadores ambientais. In: SATO, Michèle; CARVALHO, Isabel Cristina Moura. (Org.). Educação Ambiental: pesquisa e desafios. Porto Alegre: Artmed, 2005.

CARVALHO Isabel Cristina de Moura. Educação ambiental: a formação do sujeito ecológico. 4. ed. São Paulo: Cortez, 2008. 
COSTA, F. W. D; AGUIAR, P. R.

A formação da cidadania ecológica articulada à Educação Ambiental na escola

CASCINO, Fábio. Educação Ambiental: princípios, história, formação de professores. 3. ed. São Paulo: Editora SENAC, 2003.

CASTRO, Ronaldo Sousa de; BAETA, Anna Maria. Autonomia intelectual: condição necessária para o exercício da cidadania. In: LOUREIRO, Carlos Frederico Bernardo; LAYRARGUES, Philippe Pomier; CASTRO, Ronaldo Sousa de (Orgs.). Educação

Ambiental: repensando o espaço da cidadania. 4. ed. São Paulo: Cortez, 2008. cap. 4, p. 99141.

CATALÃO, Vera Lessa. Desenvolvimento sustentável e educação ambiental no Brasil. In: PÁDUA, José Augusto (Org.). Desenvolvimento, justiça e meio ambiente. Belo Horizonte: Editora UFMG; São Paulo: Peirópolis, 2009. p. 242-270.

DIAS, Genebaldo Freire. Educação ambiental: princípios e práticas. São Paulo: Brochura, 2010.

FERNANDES, Francisco Rego Chaves; LINS, Fernando Antonio Freitas; VILLAS-BÔAS, Roberto Carlos (Orgs.). Da Rio 92 à Rio+20: o CETEM e a pesquisa sustentável dos recursos minerais. Rio de Janeiro: CETEM/MCTI, 2012.

FOGLIATTI, Maria Cristina; FILIPPO, Sandro; GOUDARD, Beatriz. Avaliação de impactos ambientais: aplicação aos sistemas de transporte. São Paulo: Editora Interciência, 2004.

FREIRE, Paulo. Criando método de pesquisa alternativa: aprendendo a fazê-la melhor através da ação. In: BRANDÃO, Carlos Rodrigues (Orgs.). Pesquisa participante. 3. ed. São Paulo: Brasiliense, 1981, p. 34-41.

GONÇALVES, Candice Salerno; DIEHL, Luciana Schramm. Integrando sala e ambiente. In: LISBOA, Cassiano Pamplona; KINDEL, Eunice Aita Isaia (Orgs.). Educação Ambiental: da teoria e à prática. Porto Alegra: Mediação, 2012. p. 29-48.

GUIMARÃES, Mauro. Educação ambiental crítica. In: LAYRARGUES, Philippe. Pomier. (Coord.). Identidades da educação ambiental brasileira. Brasília: MMA, 2004, p. 27-36.

JACOBI, Pedro. Educação Ambiental, Cidadania e Sustentabilidade. Cadernos de Pesquisa, São Paulo: Fundação Carlos Chagas, v. n. 118, p. 198-205, março 2003. Disponível em: https://www.scielo.br/scielo.php?script=sci_arttext\&pid=S0100-15742003000100008. Acesso em: 22/06/2014.

LIMA, Gustavo Ferreira da Costa. Educação, emancipação e sustentabilidade: em defesa de uma pedagogia libertadora para a educação ambiental. In: LAYRARGUES, Philippe. Pomier. (Coord.). Identidades da educação ambiental brasileira. Brasília: MMA, 2004. p. 87-113.

LOUREIRO, Carlos Frederico Bernardo. Educação Ambiental Transformadora. In: LAYRARGUES, Philippe Pomier. (Coord.). Identidades da educação ambiental brasileira. Brasília: MMA, 2004. p. 67-84. 
COSTA, F. W. D; AGUIAR, P. R.

A formação da cidadania ecológica articulada à Educação Ambiental na escola

LOUREIRO, Carlos Frederico Bernardo. Educação ambiental e movimentos sociais na construção da cidadania ecológica e planetária. In: LOUREIRO, Carlos Frederico Bernardo; LAYRARGUES, Philippe Pomier; CASTRO, Ronaldo Sousa de (Orgs.). Educação Ambiental: repensando o espaço da cidadania. 4. ed. São Paulo: Cortez, 2008. cap. 3, p. 6998 .

LOUREIRO, Carlos Frederico Bernardo. Indicadores: meios para avaliação de projetos, programas e políticas públicas em Educação Ambiental. In: TOZONI-REIS, Marília Freitas Campos (Org.) Pesquisa-ação-participativa em Educação Ambiental: reflexões teóricas. São Paulo: Annablume, 2007.

LOUREIRO, Carlos Frederico Bernardo et al. Contribuições da teoria marxista para a educação ambiental crítica. Cadernos CEDES, Campinas, v. 29, n. 77, p. 81-97, 2009.

MORENO, Jacob Levy. Fundamentos de la sociometria. 2. ed. Buenos Aires: Paidós, 1972.

MELLO, Márcia Cristina de Oliveira. Projetos de Ensino em Geografia e a necessária articulação com a Educação Ambiental nas escolas. In: RISSO, Cristina (Org.). Ensino de Geografia e Educação Ambiental: relatos de experiências. Ourinhos: UNESP/Campus Experimental de Ourinhos, 2013. p. 27- 44.

NUNES, Letícia Soares; FREITAS, Rosana de Carvalho Martinelli. A Educação Ambiental e sua interlocução com o pensamento de Karl Marx. V ENCONTRO BRASILEIRO DE EDUCAÇÃO E MARXISMO. Florianópolis (SC). Anais eletrônicos... Florianópolis: UFSC, 2011. Disponível em: http://www.5ebem.ufsc.br/trabalhos/eixo_05/e05h_t005.pdf.htm. Acesso em: 14/04/2014.

PHILIPPI JUNIOR, Arlindo; PELICIONI, Maria Cecília Focesi. Alguns pressupostos da educação ambiental. In: PHILIPPI JUNIOR, Arlindo; Pelicioni, Maria Cecília Focesi (Orgs.). Educação Ambiental: desenvolvimento de cursos e projetos. 2. ed. São Paulo: Signus Editora, 2002. cap. I, p. 3-6.

PROTÁZIO, Pedro Barros. A crise socioambiental e a formação do ambientalismo brasileiro. In: SEABRA, Giovanni (Org.). Educação ambiental no mundo globalizado. João Pessoa: Editora Universitária/UFPB, 2011. cap. 7, p. 103-111.

REIGOTA, Marcos. Desafios à educação ambiental escolar. In: JACOBI, Pedro et al. (Orgs.). Educação, meio ambiente e cidadania: reflexões e experiências. São Paulo: SMA, 1998. p. 43-50.

REIGOTA, Marcos. O que é educação ambiental. 2. ed. São Paulo: Brasiliense, 2009. Coleção primeiros passos.

SANTILLI, Juliana; SANTILLI, Márcio. Desenvolvimento socioambiental: uma opção brasileira. In: PÁDUA, José Augusto (Org.). Desenvolvimento, justiça e meio ambiente. Belo Horizonte: Editora UFMG; São Paulo: Peirópolis, 2009. p. 216-241. 
COSTA, F. W. D; AGUIAR, P. R.

A formação da cidadania ecológica articulada à Educação Ambiental na escola

SANTOS, Elizabeth da Conceição; MEDINA, Naná Minnini. Educação ambiental: uma metodologia participativa de formação. Petrópolis: Vozes, 1999.

THIOLLENT, Michel. Metodologia da pesquisa-ação. São Paulo: Cortez, 2000.

TRIVIÑOS, Augusto Nibaldo Silva. Introdução à pesquisa em ciências sociais: a pesquisa qualitativa em educação. São Paulo: Atlas, 1987.

\section{Autores}

Francisco Wendell Dias Costa - É Graduado em Geografia pela Universidade Federal do Maranhão (UFMA); Mestre em Desenvolvimento Socioespacial e Regional pela Universidade Estadual do Maranhão (UEMA) e Doutor em Geografia pela Universidade Estadual Paulista "Júlio de Mesquita Filho" (UNESP), campus Presidente Prudente-SP. Atualmente é professor da Secretaria de Educação do Município de Anajatuba, Maranhão.

Patrícia Rosa Aguiar - É Graduada em Geografia Licenciatura pela Universidade Estadual de Montes Claros (UNIMONTES) e Bacharelado pela Universidade Federal de Minas Gerais (UFMG) e é Mestra em Tecnologias, Comunicação e Educação pela Universidade Federal de Uberlândia (UFU). Atualmente é Professora (EBTT) de Geografia do Instituto Federal do Triângulo Mineiro (IFTM/Campus Patrocínio-MG) e é Doutoranda em Geografia pela Pontifícia Universidade Católica de Minas Gerais (PUC-MINAS).

Artigo recebido em: 21 de julho de 2020.

Artigo aceito em: 14 de setembro de 2020.

Artigo publicado em: 21 de setembro de 2020. 